\title{
Hyperuricemia is associated with decreased changes in heart rate variability after hemodialysis in non-diabetic patients
}

\author{
Po-Chih Chen ${ }^{1,2}$, Pei-Yu Wu ${ }^{3,4,5}$, Jiun-Chi Huang ${ }^{3,4,5,6}$, Szu-Chia Chen ${ }^{3,4,5,6}$ and Yeou- \\ Lih Huang ${ }^{1,2,7}$ \\ ${ }^{1}$ Department of Medical Laboratory Science and Biotechnology, College of Health Sciences, Kaohsiung Medical University, \\ Kaohsiung, Taiwan \\ ${ }^{2}$ Department of Laboratory Medicine, Kaohsiung Medical University Hospital, Kaohsiung Medical University, Kaohsiung, \\ Taiwan \\ ${ }^{3}$ Graduate Institute of Clinical Medicine, College of Medicine, Kaohsiung Medical University, Kaohsiung, Taiwan \\ ${ }^{4}$ Division of Nephrology, Department of Internal Medicine, Kaohsiung Medical University Hospital, Kaohsiung Medical \\ University, Kaohsiung, Taiwan \\ ${ }^{5}$ Department of Internal Medicine, Kaohsiung Municipal Hsiao-Kang Hospital, Kaohsiung Medical University, Kaohsiung, \\ Taiwan \\ ${ }^{6}$ Faculty of Medicine, College of Medicine, Kaohsiung Medical University, Kaohsiung, Taiwan \\ ${ }^{7}$ Department of Chemistry, National Sun Yat-sen University, Kaohsiung, Taiwan \\ Correspondence to: Szu-Chia Chen, email: scarchenone@yahoo.com.tw \\ Yeou-Lih Huang, email: yelihu@kmu.edu.tw
}

Keywords: heart rate variability change before and after hemodialysis; hemodialysis; non-diabetes; uric acid Received: September 08, $2017 \quad$ Accepted: November 15, $2017 \quad$ Published: January 04,2018

Copyright: Chen et al. This is an open-access article distributed under the terms of the Creative Commons Attribution License 3.0 (CC BY 3.0), which permits unrestricted use, distribution, and reproduction in any medium, provided the original author and source are credited.

\section{ABSTRACT}

Hyperuricemia has been associated with low heart rate variability (HRV), however whether there is an association between uric acid (UA) and HRV changes after hemodialysis (HD) is unknown. The aim of this study was to investigate the role of UA in HRV changes before and after HD in non-diabetic patients. Ninety-six nondiabetic patients under maintenance HD were enrolled. HRV was examined to assess changes before and after HD. A change in HRV ( $\triangle H R V)$ was calculated as post-HD HRV minus pre-HD HRV. Compared to the patients with a UA level $\leqq 7 \mathrm{mg} / \mathrm{dL}$, those with a UA level $>7 \mathrm{mg} / \mathrm{dL}$ had lower $\Delta$ high frequency $(\mathrm{HF}) \%(p=0.027)$. UA was negatively associated with $\Delta \mathrm{HF} \%(r=-0.247, p=0.015)$ and $\Delta$ low frequency (LF)/ HF $(r=-0.236, p=0.021)$ in the non-diabetic patients undergoing HD. Furthermore, in multivariate analysis after adjustments for demographic, clinical, and biochemical characteristics and medications, UA was independently associated with $\triangle H F \%$ (per 1 $\mathrm{mg} / \mathrm{dL}$, unstandardized coefficient $\beta=-2.892 ; 95 \% \mathrm{CI},-5.066$ to $-0.717 ; p=0.010$ ) and $\Delta \mathrm{LF} / \mathrm{HF}$ (per $1 \mathrm{mg} / \mathrm{dL}$, unstandardized coefficient $\beta=-0.165 ; 95 \% \mathrm{CI},-0.291$ to $-0.038 ; p=0.011$ ). Hyperuricemia contributed to lesser $\mathrm{HF} \%$ and $\mathrm{LF} / \mathrm{HF}$ increase after HD in the non-diabetic patients, reflecting a state of impaired sympatho-vagal equilibrium in non-diabetic HD patients with hyperuricemia. Lowering UA levels may have the potential to improve increased HRV in non-diabetic HD patients.

\section{INTRODUCTION}

Cardiovascular autonomic neuropathy can be evaluated according to variations in heart rate, termed heart rate variability (HRV). HRV is defined as variations in R-R interval and instantaneous heart rate on electrocardiography, and it has been shown to be a simple and noninvasive method to assess autonomic nervous system activity [1]. HRV can be categorized as being high-frequency (HF) and low-frequency (LF) [1]. HF 
HRV is analogous to respiratory sinus arrhythmia, and it can be used to characterize vagal control of the heart rate [2]. Both vagal and sympathetic activities have been reported to contribute to LF HRV [3], and normalized LF (LF\%) and the LF/HF ratio have been reported to reflect sympatho-vagal balance and sympathetic modulation [1]. HRV (low LF and HF) has been shown to be drastically decreased in patients undergoing chronic hemodialysis (HD) compared to healthy controls, implying increased autonomic dysfunction and sympathetic activation [4]. In addition, low HRV has been associated with adverse cardiovascular outcomes in chronic HD patients [5-7]. Moreover, dialysis-induced changes are consistent with compensatory baroreflex-mediated activation of the sympathetic nervous system according to HRV in HD patients [8]. We recently reported that changes in HRV before and after HD $(\Delta \mathrm{HRV})$ can be used to predict overall and cardiovascular mortality [9]. Zitt et al. [10] also evaluated the association between diabetes and autonomic cardiovascular regulation during HD. In their study, eight diabetic patients showed a blunted autonomic response, whereas HRV was found to be increased during dialysis in nine non-diabetic patients [8]. Impaired autonomic function may therefore be related to damage due to diabetes in autonomic neuropathy. Although a previous study investigated the factors related to $\triangle H R V$ in non-diabetic HD patients, it was limited by a small sample size [11].

Many epidemiological studies have reported that hyperuricemia is independently associated with increased mortality, cardiovascular disease, and renal disease in the general population $[12,13]$. Hyperuricemia is common in patients with renal failure, possibly due to decreased renal excretion of uric acid (UA) in patients with impaired renal function. In addition, hyperuricemia has been associated with various risk factors for renal failure [12, 14, 15]. Previous studies have reported an association between hyperuricemia and low HRV parameters in various populations [16-18]. However, few studies have evaluated the relationship between UA and changes in HRV before and after HD. Therefore, the aim of this study was to assess the role of UA in HRV changes before and after HD in non-diabetic patients.

\section{RESULTS}

The mean age of the 96 patients was $59.8 \pm 12.2$ years. Comparisons of baseline characteristics between the patients with a UA level $\leqq 7 \mathrm{mg} / \mathrm{dL}$ and those with a UA level $>7$ $\mathrm{mg} / \mathrm{dL}$ are shown in Table 1. Compared to the patients with a UA level $\leqq 7 \mathrm{mg} / \mathrm{dL}$, those with a level $>7 \mathrm{mg} / \mathrm{dL}$ were younger, had higher levels of albumin, creatinine, and total calcium, and lower rates of $\beta$-blocker and calcium channel blocker use. In addition, the patients with UA $>7 \mathrm{mg} / \mathrm{dL}$ had a lower $\Delta$ high $\mathrm{HF} \%$.

\section{Correlations between $\mathrm{UA}$ and $\triangle \mathrm{HRV}$ parameters}

Correlations between UA and $\triangle \mathrm{HRV}$ parameters in the non-diabetic HD patients are shown in Table 2. UA was negatively associated with $\Delta \mathrm{HF} \%(r=-0.247, p=$ $0.015)$ and $\Delta \mathrm{LF} / \mathrm{HF}(r=-0.236, p=0.021)$. However, UA was not correlated with $\Delta \mathrm{LF}(p=0.264), \Delta \mathrm{HF}(p=0.890)$ or $\Delta \mathrm{LF} \%(p=0.115)$.

\section{Determinants of $\triangle \mathrm{HF} \%$}

The multiple stepwise analysis Table 3 revealed that $\triangle \mathrm{HF} \%$ was independently correlated with potassium (per 1 $\mathrm{mEq} / \mathrm{L}$, unstandardized coefficient $\beta=6.868 ; 95 \%$ confidence interval [CI], 2.109 to $11.628 ; p=0.005$ ), total calcium (per 1 $\mathrm{mg} / \mathrm{dL}$, unstandardized coefficient $\beta=5.177 ; 95 \% \mathrm{CI}, 1.776$ to $8.578 ; p=0.003$ ) and $\mathrm{UA}$ (per $1 \mathrm{mg} / \mathrm{dL}$, unstandardized coefficient $\beta=-2.892 ; 95 \%$ CI, -5.066 to $-0.717 ; p=0.010$ ) after adjusting for age, sex, hypertension, duration of dialysis, a history of smoking, coronary artery disease, cerebrovascular disease, systolic blood pressure, diastolic blood pressure, levels of albumin, fasting glucose, triglyceride, total cholesterol, hemoglobin, creatinine, potassium, total calcium, phosphorous, calcium-phosphorous product, intact parathyroid hormone (iPTH), and UA, Kt/ $\mathrm{V}$, percentage of ultrafiltration, and medications including calcium channel blockers, $\beta$-blockers, angiotensin converting enzyme inhibitors (ACEIs), angiotensin II receptor blockers (ARBs), and statins.

\section{Determinants of $\Delta \mathrm{LF} / \mathrm{HF}$}

The multiple stepwise analysis Table 3 revealed that $\triangle \mathrm{LF} / \mathrm{HF}$ was independently correlated with potassium (per $1 \mathrm{mEq} / \mathrm{L}$, unstandardized coefficient $\beta=0.462 ; 95 \%$ CI, 0.185 to $0.739 ; p=0.001$ ), total calcium (per $1 \mathrm{mg} / \mathrm{dL}$, unstandardized coefficient $\beta=0.284 ; 95 \% \mathrm{CI}, 0.086$ to 0.483 ; $p=0.005$ ) and $\mathrm{UA}$ (per $1 \mathrm{mg} / \mathrm{dL}$, unstandardized coefficient $\beta=-0.165 ; 95 \% \mathrm{CI},-0.291$ to $-0.038 ; p=0.011$ ).

\section{Risk of hospitalization}

The median and range of follow-up period was 27.3 (1.5-38) months for all patients. During the follow-up period, 49 hospitalizations were recorded among these 96 patients (51.0\%), including CV events $(n=13)$, gastrointestinal disorders or bleeding $(n=5)$, infectious diseases or sepsis $(n=13)$, malignancy $(\mathrm{n}=8)$, musculoskeletal disorders or fractures $(n=4)$, complications of arteriovenous access $(n=2)$, and others $(n=4)$. Table 4 shows the predictors for hospitalization. In the multivariate forward analysis, cerebrovascular disease, low albumin, high fasting glucose, high hemoglobin, high CaXP product and low LF (hazard ratios, $0.875 ; 95 \% \mathrm{CI}, 0.814-0.941 ; p<0.001$ ) were independently associated with increased hospitalization. 
Table 1: Comparison of baseline characteristics between non-diabetic hemodialysis patients with uric acid $\leqq 7 \mathrm{mg} / \mathrm{dL}$ and $>7 \mathrm{mg} / \mathrm{dL}$

\begin{tabular}{|c|c|c|c|c|}
\hline Characteristics & $\begin{array}{c}\text { All patients }(n= \\
96)\end{array}$ & $\begin{array}{l}\text { With uric acid } \leqq 7 \\
\mathrm{mg} / \mathrm{dL}(n=30)\end{array}$ & $\begin{array}{c}\text { With uric acid }>7 \\
\mathrm{mg} / \mathrm{dL}(n=66)\end{array}$ & $P$ \\
\hline Age (year) & $59.8 \pm 12.2$ & $64.4 \pm 14.2$ & $57.7 \pm 10.6$ & 0.012 \\
\hline Male gender $(\%)$ & 36.5 & 36.7 & 36.4 & 0.977 \\
\hline Duration of dialysis (years) & $8.4(4.6-12.7)$ & $7.8(4.7-12.7)$ & $8.7(4.6-12.5)$ & 0.650 \\
\hline Smoking history (\%) & 24.0 & 23.3 & 24.2 & 0.923 \\
\hline Hypertension (\%) & 50.0 & 56.7 & 47.0 & 0.378 \\
\hline Coronary artery disease $(\%)$ & 17.7 & 16.7 & 18.2 & 0.857 \\
\hline Cerebrovascular disease $(\%)$ & 3.1 & 3.3 & 3.0 & 0.937 \\
\hline Systolic blood pressure $(\mathrm{mmHg})$ & $144.1 \pm 23.2$ & $143.9 \pm 22.7$ & $144.1 \pm 23.6$ & 0.973 \\
\hline Diastolic blood pressure (mmHg) & $79.9 \pm 13.5$ & $79.9 \pm 12.2$ & $79.9 \pm 14.1$ & 0.998 \\
\hline \multicolumn{5}{|l|}{ Laboratory parameters } \\
\hline Albumin (g/dL) & $3.9 \pm 0.3$ & $3.8 \pm 0.2$ & $3.9 \pm 0.3$ & 0.020 \\
\hline Fasting glucose (mg/dL) & $98.2 \pm 26.0$ & $99.7 \pm 24.0$ & $97.5 \pm 27.1$ & 0.710 \\
\hline Triglyceride (mg/dL) & $118(87-199)$ & $137(91.3-189.5)$ & $108(85.5-201)$ & 0.494 \\
\hline Total cholesterol (mg/dL) & $188.1 \pm 39.6$ & $183.7 \pm 35.9$ & $190.2 \pm 41.2$ & 0.464 \\
\hline Hemoglobin $(\mathrm{g} / \mathrm{dL})$ & $10.2 \pm 1.0$ & $10.2 \pm 1.1$ & $10.1 \pm 1.0$ & 0.843 \\
\hline Creatinine (mg/dL) & $10.0 \pm 2.2$ & $8.7 \pm 2.1$ & $10.7 \pm 2.0$ & $<0.001$ \\
\hline Potassium (mEq/L) & $4.5 \pm 0.8$ & $4.6 \pm 0.9$ & $4.5 \pm 0.7$ & 0.414 \\
\hline Total calcium $(\mathrm{mg} / \mathrm{dL})$ & $9.5 \pm 1.1$ & $9.1 \pm 1.2$ & $9.7 \pm 1.0$ & 0.015 \\
\hline Phosphorous (mg/dL) & $4.4 \pm 1.0$ & $4.4 \pm 1.0$ & $4.4 \pm 1.0$ & 0.808 \\
\hline CaXP product $\left(\mathrm{mg}^{2} / \mathrm{dL}^{2}\right)$ & $41.8 \pm 10.4$ & $39.4 \pm 8.9$ & $42.9 \pm 10.9$ & 0.136 \\
\hline iPTH (pg/mL) & $391.1(184.9-487.6)$ & $392.9(128.4-421.2)$ & $385(197.1-643.1)$ & 0.579 \\
\hline Uric acid $(\mathrm{mg} / \mathrm{dL})$ & $7.9 \pm 1.6$ & $6.3 \pm 0.6$ & $8.7 \pm 1.4$ & $<0.001$ \\
\hline $\mathrm{Kt} / \mathrm{V}$ (Daugirdes) & $1.6 \pm 0.3$ & $1.7 \pm 0.4$ & $1.6 \pm 0.2$ & 0.272 \\
\hline Ultrafiltration (\%) & $4.1 \pm 1.4$ & $4.1 \pm 1.5$ & $4.1 \pm 1.4$ & 0.985 \\
\hline \multicolumn{5}{|l|}{$\Delta \mathrm{HRV}$ parameters (frequency domain) } \\
\hline$\Delta \mathrm{LF}\left(\mathrm{ms}^{2}\right)$ & $0.16 \pm 0.47$ & $1.06 \pm 0.32$ & $-0.25 \pm 0.66$ & 0.194 \\
\hline$\Delta \mathrm{HF}\left(\mathrm{ms}^{2}\right)$ & $0.22 \pm 0.37$ & $0.51 \pm 0.36$ & $0.09 \pm 0.52$ & 0.606 \\
\hline$\Delta \mathrm{LF} \%(\mathrm{nu})$ & $-4.66 \pm 2.3$ & $-10.34 \pm 4.58$ & $-2.09 \pm 2.61$ & 0.099 \\
\hline$\Delta \mathrm{HF} \%(\mathrm{nu})$ & $2.06 \pm 1.71$ & $7.63 \pm 3.67$ & $-0.47 \pm 1.78$ & 0.027 \\
\hline$\Delta \mathrm{LF} / \mathrm{HF}$ & $0.22 \pm 0.12$ & $0.56 \pm 0.23$ & $0.07 \pm 0.13$ & 0.057 \\
\hline \multicolumn{5}{|l|}{ Medications } \\
\hline ACEI and/or ARB use & 13.6 & 14.8 & 13.1 & 0.830 \\
\hline$\beta$-blocker use & 14.8 & 33.3 & 6.6 & 0.002 \\
\hline Calcium channel blocker use & 18.2 & 37.0 & 9.8 & 0.002 \\
\hline Statins use & 20.5 & 14.8 & 23.0 & 0.568 \\
\hline
\end{tabular}

Abbreviations. CaXP product, Calcium-phosphorous product; iPTH, intact parathyroid hormone; HRV, heart rate variability; LF, low frequency; HF, high frequency; ACEI, angiotensin converting enzyme inhibitor; ARB, angiotensin II receptor blocker.

\section{DISCUSSION}

The present study evaluated the relationship between UA and changes in HRV before and after HD in non-diabetic patients. The results showed that the patients with a higher UA level were associated with decreased $\mathrm{HF} \%$ and $\mathrm{LF} / \mathrm{HF}$ increase after HD. In addition, higher levels of potassium and total calcium were positively correlated with changes in HRV parameters before and after HD in the study patients. 
Table 2: Correlation between uric acid and $\triangle \mathrm{HRV}$ parameters in non-diabetic hemodialysis patients

\begin{tabular}{ccc}
\hline$\Delta$ HRV parameters & Pearson's $\mathbf{r}$ & $\boldsymbol{p}$ \\
\hline$\Delta \mathrm{LF}\left(\mathrm{ms}^{2}\right)$ & -0.115 & 0.264 \\
$\Delta \mathrm{HF}\left(\mathrm{ms}^{2}\right)$ & -0.014 & 0.890 \\
$\Delta \mathrm{LF} \%(\mathrm{nu})$ & 0.162 & 0.115 \\
$\Delta \mathrm{HF} \%(\mathrm{nu})$ & -0.247 & 0.015 \\
$\Delta \mathrm{LF} / \mathrm{HF}$ & -0.236 & 0.021 \\
\hline
\end{tabular}

Values expressed as r. Abbreviations are the same as in Table 1.

The most important finding of the present study is that hyperuricemia contributed to a smaller increase in HRV after HD in non-diabetic patients. HRV is a noninvasive method that can be used to assess the autonomic nervous system. It represents beat-to-beat variability in heart rate, and it has successfully been used in patients undergoing chronic dialysis [19]. Abnormalities in HRV primarily reflect dysregulation between the sympathetic and parasympathetic nervous systems. An increasing number of studies have applied HRV frequency-domain analysis to assess the autonomic nervous system due to its non-invasiveness and easy applicability. Previous studies have reported that hyperuricemia is associated with low values of HRV parameters in pregnancy women and ageing population $[16,17]$. Hyperuricemia has been associated with factors related to insulin resistance including obesity, dyslipidemia and hypertension $[14,20,21]$. Several mechanisms have been proposed for alterations in cardiac autonomic function underlying the pathogenesis of insulin resistance [22]. Sympathetic activation has been shown to inhibit insulin secretion from beta cells in the pancreas, leading to reduced glucose transport to peripheral tissues [23]. In addition, sympathetic vasoconstriction can cause a reduction in blood flow thereby reducing the uptake of glucose in skeletal muscles, and this can result in a reduction in the number of available capillaries and an increase in the distance that insulin has to travel to the cell membranes [22]. Moreover, sympathetic activation has been shown to increase adipose tissue lipolysis and the level of circulating free fatty acid [24]. This may then lead to an increase in insulin resistance and potentially hyperinsulinemia, and this can induce central sympathetic outflow resulting in a vicious circle [24]. The proposed association between hyperuricemia and autonomic dysfunction could be explained by the commonly seen insulin resistance in HD patients, which has been shown to be correlated with low HRV [25]. Moreover, we found an association between hyperuricemia and decreased $\triangle \mathrm{HRV}$ after HD in our non-diabetic patients. Therefore, lowering UA levels may have the potential to improve increased HRV in non-diabetic HD patients. However, further studies are needed to confirm this hypothesis.

The second important finding of this study is that an increased potassium level was associated with increased changes in HRV parameters before and after HD. Membrane potential is primarily governed by the permeability of a membrane to potassium ions and the concentration gradient, and to some extent by the $\mathrm{Na}+/ \mathrm{K}+$ pump. The potassium gradient plays a vital role in many physiological processes, including transmitting action potentials in nerve cells, maintaining cellular membrane potential, and cell volume homeostasis [26]. Higher levels of extracellular potassium can result in cell membrane potential depolarization through an increased potassium equilibrium potential. When the level of potassium exceeds a certain level, this depolarization opens potassium channels and inactivates sodium channels, thereby causing the cells to become refractory. This can then lead to neuromuscular, cardiac, and gastrointestinal organ system impairments, which in turn can cause ventricular fibrillation, an abnormally slow heart rhythm, and asystole [26]. Another possible explanation is that decreased serum potassium during $\mathrm{HD}$ is negatively correlated with the basal intracellular potassium concentration [26]. This loss of serum potassium then results in a lower threshold for cell depolarization, thereby increasing QT variation and inducing cardiac arrhythmia [27] which could theoretically affect HRV.

Zhang et al. [28] investigated the relationship between mineral metabolism and HRV in patients with stage 5 chronic kidney disease, and found significant associations between low HRV parameters and abnormal levels of serum calcium, iPTH and phosphorous, and that parathyroidectomy may reverse the risk of cardiovascular disease [28]. These findings suggest that both dysregulation of cardiovascular autonomic control and abnormal mineral metabolism may contribute to the higher risk of cardiovascular disease. In the present study, we found that a higher total calcium level was associated with greater changes in HRV parameters before and after HD. Therefore, a higher level of calcium may be associated with increased sympathetic activity, decreased arterial compliance and intradialytic hypertension [29, 30]. A higher calcium level has been reported to be associated with an increase in myocardial contractility [31], which may explain our findings.

There are several limitations to this study. First, the number of patients was relatively small, which may have affected the results. In future studies, we will enroll a larger number of patients. Second, this study was crosssectional, and causal relationships could not be confirmed. In addition, heart rate autonomic modulation follows a 


\begin{tabular}{lcc}
\hline$\Delta$ HRV parameters & Multivariate (Stepwise) & $\boldsymbol{p}$ \\
\cline { 2 - 3 } & \multicolumn{1}{c}{ Unstandardized coefficient $\boldsymbol{\beta}$ (95\% CI) } & 0.005 \\
\hline HF\% & & 0.003 \\
Potassium (per 1 mEq/L) & $5.177(1.776,8.578)$ & 0.010 \\
Total calcium (per 1 mg/dL) & $-2.892(-5.066,-0.717)$ & \\
Uric acid (per 1 mg/dL) & & 0.001 \\
$\Delta$ LF/HF & $0.462(0.185-0.739)$ & 0.005 \\
Potassium (per 1 mEq/L) & $0.284(0.086-0.483)$ & 0.011 \\
Total calcium (per 1 mg/dL) & $-0.165(-0.291,-0.038)$ & \\
Uric acid (per 1 mg/dL) & & \\
\hline
\end{tabular}

Values expressed as unstandardized coefficient $\beta$ and 95\% confidence interval (CI). Abbreviations are the same as in Table 1. Covariates in the multivariate model included age, sex, duration of dialysis, a history of smoking, hypertension, coronary artery disease and cerebrovascular disease, systolic and diastolic blood pressure, albumin, fasting glucose, triglyceride, total cholesterol, hemoglobin, creatinine, potassium, total calcium, phosphorous, $\mathrm{CaXP}$ product, $\mathrm{iPTH}$, uric acid, $\mathrm{Kt} / \mathrm{V}$, ultrafiltration percent, and medications including ACEIs and/or ARBs, $\beta$-blockers, calcium channel blockers, and statins.

circadian rhythm, with lower HRV during the day due to higher sympathetic activity, and higher HRV during the night due to vagal modulation. We performed all HRV examinations during the day (between 8 a.m. and 5 p.m.) to minimize the influence of the circadian rhythm, however we cannot rule out the possibility that this rhythm may not have been followed in all of the patients. Lastly, we did not evaluate the effect of anti-hypertensive medications on autonomic nerve function because this study was not a clinical trial aimed at investigating the effects of medications. However, the use of $\beta$-blockers, the most commonly used drug that can interfere with autonomic response, was not associated with any of our results.

In conclusion, our results showed that hyperuricemia contributed to a smaller increase in HRV after HD in patients without diabetes, reflecting a state of impaired sympatho-vagal equilibrium in non-diabetic patients with hyperuricemia undergoing HD. Lowering UA levels may therefore have the potential to improve increases in HRV in non-diabetic HD patients. In addition, high levels of potassium and total calcium were associated with greater changes in HRV after HD.

\section{MATERIALS AND METHODS}

\section{Study patients and design}

This study was conducted at a regional hospital in southern Taiwan. We included all patients undergoing maintenance HD except for those receiving HD during night shifts. In total, we enrolled 96 non-diabetic patients (35 males and 61 females) from May 2012 to July 2012. The study protocol was approved by our Institutional Review Board, and all of the enrolled patients provided written informed consent. All of the patients received HD three times per week, with each session lasting 3.5-4.5 hours with a blood flow rate of $250-300 \mathrm{~mL} / \mathrm{min}$ and dialysate flow of $500 \mathrm{~mL} / \mathrm{min}$. Blood samples were taken before and after $\mathrm{HD}$ to calculate $\mathrm{Kt} / \mathrm{V}$.

\section{Electrocardiogram signal processing}

All of the recruited subjects received short-term power spectral analysis of HRV, with all measurements being conducted in a quiet, temperature-controlled $\left(28^{\circ} \mathrm{C}\right)$ room. HRV was analyzed according to standard methods. [32-34] A pericardial electrocardiogram (ECG) was performed continuously for 5 minutes with the patient lying quietly and breathing normally in the supine position for at least 10 minutes. The patients received these ECG examinations 30 minutes before and after the HD sessions, which were performed during the day (between 8 a.m. and 5 p.m.). ECG signals were recorded using an HRV analyzer (SS1C, Enjoy Research, Taipei, Taiwan) with an analog-to-digital converter and sampling rate of $256 \mathrm{~Hz}$. Digitized ECG signals were analyzed online and stored on a computer for off-line verification. A computer program was used to identify each QRS complex, and ventricular premature complexes and noise were rejected according to a standard QRS template. Constant R-R values were measured again and interpolated at a rate of $7.11 \mathrm{~Hz}$ to achieve consistency in the time domain [33].

\section{HRV frequency-domain analysis}

Non-parametric fast Fourier transformation (FFT) was used to analyze the frequency-domain. Following deletion of the direct current component, a Hamming window was used to reduce the effect of leakage [35]. Power spectrum density was estimated for each time segment (288 s; 2048 data points) using a computer algorithm based on FFT. Attenuation 
Table 4: Predictors for hospitalization using Cox proportional hazards model

\begin{tabular}{lcc}
\hline Outcome & Multivariate (forward) & \\
\cline { 2 - 3 } & & $\boldsymbol{p}$ \\
\hline Hospitalization & & 0.005 \\
Cerebrovascular disease & $5.673(1.668-19.295)$ & 0.002 \\
Albumin (per 1 g/dL) & $0.188(0.064-0.551)$ & 0.020 \\
Fasting glucose (pre 1 mg/dL) & $1.011(1.002-1.019)$ & 0.005 \\
Hemoglobin (per 1 g/dL) & $1.487(1.127-1.962)$ & 0.015 \\
CaXP product (per 1 mg $\left./ \mathrm{dL}^{2}\right)$ & $1.034(1.007-1.262)$ & $<0.001$ \\
LF (per 1 $\left.\mathrm{ms}^{2}\right)$ & $0.875(0.814-0.941)$ & CI) \\
\hline
\end{tabular}

Values expressed as Hazard Ratios and 95\% confidence interval (CI). Abbreviations are the same as in Table 1.

Covariates in the multivariate model include age, sex, duration of dialysis, a history of smoking, hypertension, coronary artery disease and cerebrovascular disease, systolic and diastolic blood pressure, albumin, fasting glucose, triglyceride, total cholesterol, hemoglobin, creatinine, potassium, total calcium, phosphorous, CaXP product, iPTH, uric acid, Kt/V and HRV parameters before hemodialysis. Forward stepwise selection included variables with entry and removal probability $<0.05$.

of this power spectrum caused by the sampling and Hamming window was then corrected, followed by quantification into standard frequency-domain parameters, [1] including LF $(0.04-0.15 \mathrm{~Hz}), \mathrm{HF}$ $(0.15-0.40 \mathrm{~Hz})$ and LF/HF HRV. LF and HF were normalized to the percentage of total power to detect any sympathetic influence on HRV as follows: LF\% = $\mathrm{LF} /$ (total power-VLF [very low frequency])*100, and $\mathrm{HF} \%=\mathrm{HF} /$ (total power-VLF) $* 100$. All of the HRV parameters were then logarithmically transformed to reduce skewness of distribution [1]. HF can be used to represent respiratory sinus arrhythmia and vagal control of heart rate [2]. Both vagal and sympathetic activity have been reported to contribute to LF HRV [3], and normalized values of LF (LF\%) and the LF/HF ratio have been reported to reflect sympatho-vagal balance or sympathetic modulation [1]. Changes in HRV $(\Delta H R V)$ were assessed before and after HD, and calculated as post-HD HRV minus pre-HD HRV.

\section{Collection of demographic, medical, and laboratory data}

Demographic and medical data including age, gender and co-morbidities were obtained from the patients' medical records and interviews. were measured from Fasting blood samples were taken for assessments of laboratory data, which were measured using an autoanalyzer (Roche Diagnostics GmbH, D-68298 Mannheim COBAS Integra 400). Concentrations of serum iPTH were measured using a two-sided immunoradiometric assay (CIS Bio International, Saclay, France). Kt/V was measured using the procedure described by Daugirdas as a marker of the efficiency of dialysis [36]. Data regarding the use of $\beta$-blockers, calcium channel blockers, ARBs, ACEIs and statins during the study period were also recorded from the patients' medical records.

\section{Outcome of hospitalization}

Clinical outcome of hospitalization was assessed. Model for hospitalization was censored when patients had hospitalization from any cause or at the end of the followup until June 2015.

\section{Statistical analysis}

All statistical analyses were performed using SPSS version 17.0 for Windows (SPSS Inc., Chicago, USA). Data are expressed as percentage, mean \pm standard deviation, or mean \pm standard error of the mean for $\triangle \mathrm{HRV}$ parameters, or median (25th-75th percentile) for the duration of dialysis and levels of triglycerides and iPTH. Differences between groups were assessed using the chi-square test for categorical variables, the independent $t$-test for continuous variables with an approximately normal distribution, or the Mann-Whitney $U$ test for continuous variables with skewed distribution. Relationships between UA and $\triangle \mathrm{HRV}$ parameters were assessed using bivariate correlations (Pearson's correlation). $\triangle \mathrm{HRV}$ parameters were defined as the HRV parameters measured after HD minus those measured before HD. Multiple stepwise linear regression analysis was used to identify the factors associated with the $\triangle \mathrm{HRV}$ parameters. Multiple forward stepwise Cox proportional hazard analysis was used to identify the factors associated with hospitalization. A $p$ value of less than 0.05 was considered to be statistically significant.

\section{Abbreviations}

heart rate variability (HRV), hemodialysis (HD), uric acid (UA), high frequency (HF), low frequency (LF), intact parathyroid hormone (iPTH), angiotensin converting enzyme inhibitors (ACEIs), angiotensin II receptor blockers (ARBs), electrocardiogram (ECG), Fourier transformation (FFT), very low frequency (VLF). 


\section{Author contributions}

Conceived and designed the experiments: P.C.C., P.Y.W., J.C.H., S.C.C. and Y.L.H. Performed the experiments: P.C.C., P.Y.W., J.C.H., S.C.C. and Y.L.H. Analyzed the data: P.C.C. and S.C.C. Prepare Tables and Figure: P.C.C. and S.C.C. Wrote the paper: P.C.C. and S.C.C. All authors reviewed the manuscript.

\section{CONFLICTS OF INTEREST}

We have no financial interest in the information contained in the manuscript.

\section{REFERENCES}

1. Task Force of the European Society of Cardiology and the North American Society of Pacing and Electrophysiology. Heart rate variability: standards of measurement, physiological interpretation and clinical use. Circulation. 1996; 93:1043-65.

2. Fouad FM, Tarazi RC, Ferrario CM, Fighaly S, Alicandri C. Assessment of parasympathetic control of heart rate by a noninvasive method. Am J Physiol. 1984; 246:H838-842.

3. Berger RD, Saul JP, Cohen RJ. Transfer function analysis of autonomic regulation. I. Canine atrial rate response. Am J Physiol. 1989; 256:H142-152.

4. Steinberg AA, Mars RL, Goldman DS, Percy RF. Effect of end-stage renal disease on decreased heart rate variability. Am J Cardiol. 1998; 82:1156-1158, A10.

5. Fukuta H, Hayano J, Ishihara S, Sakata S, Mukai S, Ohte N, Ojika K, Yagi K, Matsumoto H, Sohmiya S, Kimura G. Prognostic value of heart rate variability in patients with end-stage renal disease on chronic haemodialysis. Nephrol Dial Transplant. 2003; 18:318-325.

6. Oikawa K, Ishihara R, Maeda T, Yamaguchi K, Koike A, Kawaguchi H, Tabata Y, Murotani N, Itoh H. Prognostic value of heart rate variability in patients with renal failure on hemodialysis. Int J Cardiol. 2009; 131:370-377.

7. Huang JC, Kuo IC, Tsai YC, Lee JJ, Lim LM, Chen SC, Chiu YW, Chang JM, Chen HH. Heart rate variability predicts major adverse cardiovascular events and hospitalization in maintenance hemodialysis patients. Kidney Blood Press Res. 2017; 42:76-88.

8. Barnas MG, Boer WH, Koomans HA. Hemodynamic patterns and spectral analysis of heart rate variability during dialysis hypotension. J Am Soc Nephrol. 1999; 10:2577-2584.

9. Chen SC, Huang JC, Tsai YC, Hsiu-Chin Mai RN, JuiHsin Chen RN, Kuo PL, Chang JM, Hwang SJ, Chen HC. Heart rate variability change before and after hemodialysis is associated with overall and cardiovascular mortality in hemodialysis. Sci Rep. 2016; 6:20597.

10. Zitt E, Neyer U, Meusburger E, Tiefenthaler M, Kotanko P, Mayer G, Rosenkranz AR. Effect of dialysate temperature and diabetes on autonomic cardiovascular regulation during hemodialysis. Kidney Blood Press Res. 2008; 31:217-225.

11. Tong YQ, Hou HM. Alteration of heart rate variability parameters in nondiabetic hemodialysis patients. Am J Nephrol. 2007; 27:63-69.

12. Feig DI, Kang DH, Johnson RJ. Uric acid and cardiovascular risk. N Engl J Med. 2008; 359:1811-1821.

13. Nakagawa T, Kang DH, Feig D, Sanchez-Lozada LG, Srinivas TR, Sautin Y, Ejaz AA, Segal M, Johnson RJ. Unearthing uric acid: An ancient factor with recently found significance in renal and cardiovascular disease. Kidney Int. 2006; 69:1722-1725.

14. Johnson RJ, Feig DI, Herrera-Acosta J, Kang DH. Resurrection of uric acid as a causal risk factor in essential hypertension. Hypertension. 2005; 45:18-20.

15. Kodama S, Saito K, Yachi Y, Asumi M, Sugawara A, Totsuka K, Saito A, Sone H. Association between serum uric acid and development of type 2 diabetes. Diabetes Care. 2009; 32:1737-1742.

16. Tejera E, Areias MJ, Rodrigues AI, Ramoa A, Nieto-Villar JM, Rebelo I. Relationship between heart rate variability indexes and common biochemical markers in normal and hypertensive third trimester pregnancy. Hypertens Pregnancy. 2012; 31:59-69.

17. Felber Dietrich D, Schindler C, Schwartz J, Barthélémy JC, Tschopp JM, Roche F, von Eckardstein A, Brändli O, Leuenberger P, Gold DR, Gaspoz JM, AckermannLiebrich U, and SAPALDIA Team. Heart rate variability in an ageing population and its association with lifestyle and cardiovascular risk factors: results of the SAPALDIA study. Europace. 2006; 8:521-29.

18. Kunikullaya KU, Purushottam N, Prakash V, Mohan S, Chinnaswamy R. Correlation of serum uric acid with heart rate variability in hypertension. Hipertens Riesgo Vasc. 2015; 32:133-141.

19. Daugirdas JT. Pathophysiology of dialysis hypotension: An update. AmJ Kidney Dis. 2001; 38:S11-17.

20. Doehner W, Schoene N, Rauchhaus M, Leyva-Leon F, Pavitt DV, Reaveley DA, Schuler G, Coats AJ, Anker SD, Hambrecht R. Effects of xanthine oxidase inhibition with allopurinol on endothelial function and peripheral blood flow in hyperuricemic patients with chronic heart failure: Results from 2 placebo-controlled studies. Circulation. 2002; 105:2619-2624.

21. Saito M, Ishimitsu T, Minami J, Ono H, Ohrui M, Matsuoka H. Relations of plasma high-sensitivity c-reactive protein to traditional cardiovascular risk factors. Atherosclerosis. 2003; 167:73-79.

22. Mancia G, Bousquet P, Elghozi JL, Esler M, Grassi G, Julius S, Reid J, Van Zwieten PA. The sympathetic nervous system and the metabolic syndrome. J Hypertens. 2007; 25:909-920.

23. Carnethon MR, Prineas RJ, Temprosa M, Zhang ZM, Uwaifo G, Molitch ME, and Diabetes Prevention Program Research Group. The association among autonomic nervous 
system function, incident diabetes, and intervention arm in the Diabetes Prevention Program. Diabetes Care. 2006; 29:914-19.

24. Benthem L, Keizer K, Wiegman CH, de Boer SF, Strubbe JH, Steffens AB, Kuipers F, Scheurink AJ. Excess portal venous long-chain fatty acids induce syndrome $\mathrm{x}$ via hpa axis and sympathetic activation. Am J Physiol Endocrinol Metab. 2000; 279:E1286-1293.

25. Aso Y, Fujiwara Y, Inukai T, Takemura Y. Power spectral analysis of heart rate variation in diabetic patients with neuropathic foot ulceration. Diabetes care. 1998; 21:11731177.

26. Hill AG, Teo W, Still A, Parry BR, Plank LD, Hill GL. Cellular potassium depletion predisposes to hypokalaemia after oral sodium phosphate. Aust N Z J Surg. 1998; 68:856-858.

27. Furuland H, Linde T, Englund A, Wikstrom B. Heart rate variability is decreased in chronic kidney disease but may improve with hemoglobin normalization. J Nephrol. 2008; 21:45-52.

28. Zhang J, Yu X, Sun B, Bai J, Wei Y, Zha X, Cui Y, Zeng M, Zhang J, Liu J, Mao H, Zhang B, Ren H, et al. Parathyroidectomy and heart rate variability in patients with stage 5 ckd. Clin J Am Soc Nephrol. 2013; 8:1378-1387.

29. Chou KJ, Lee PT, Chen CL, Chiou CW, Hsu CY, Chung HM, Liu CP, Fang HC. Physiological changes during hemodialysis in patients with intradialysis hypertension. Kidney Int. 2006; 69:1833-1838.

30. Sherman RA, Bialy GB, Gazinski B, Bernholc AS, Eisinger RP. The effect of dialysate calcium levels on blood pressure during hemodialysis. AmJ Kidney Dis. 1986; 8:244-247.

31. Henrich WL, Hunt JM, Nixon JV. Increased ionized calcium and left ventricular contractility during hemodialysis. New Engl J Med. 1984; 310:19-23.

32. Chen CJ, Kuo TB, Tseng YJ, Yang CC. Combined cardiac sympathetic excitation and vagal impairment in patients with non-organic erectile dysfunction. Clin Neurophysiol. 2009; 120:348-352.

33. Kuo TB, Lin T, Yang CC, Li CL, Chen CF, Chou P. Effect of aging on gender differences in neural control of heart rate. Am J Physiol. 1999; 277:H2233-2239.

34. Liu CC, Kuo TB, Yang CC. Effects of estrogen on genderrelated autonomic differences in humans. Am J Physiol Heart Circ Physiol. 2003; 285:H2188-2193.

35. Kuo TB, Chan SH. Continuous, on-line, real-time spectral analysis of systemic arterial pressure signals. Am J Physiol. 1993; 264:H2208-2213.

36. Daugirdas JT. Simplified equations for monitoring kt $/ \mathrm{v}$, pcrn, ekt/v, and epcrn. Adv Ren Replace Ther. 1995; 2:295-304. 